\title{
When it comes to mental health, we cannot hide from reality anymore
}

\author{
Stefan Fernández-Zambrano* \\ Department of Psychiatry, University Hospital "Dr. Jose E. González”, Autonomous University of Nuevo Leon, Monterrey, Nuevo Leon, Mexico
}

Around the celebration of World Mental Health Day, it is important to take a moment to think about the alarming numbers presented by the World Health Organization. Depression ranks third among the most common diseases in the population worldwide. About $50 \%$ of mental conditions in teenagers develop before the age of 14. Suicide is the second most common cause of death in young people between the ages of 14 and 29 , and 800,000 people die every year as a result of this.

In the US, the numbers reported by the National Alliance of Mental IIIness in 2018 are as follows: yearly, one in five adults suffer from a mental disorder, one in 25 adults suffer from a major mental illness, and suicide accounts for the second most common cause of death in people between 10 and 34. Mental illnesses cost the US economy 193.2 billion dollars/year, and depression is the main cause of incapacity around the world.

One of the challenges we face today is the improvement of communication and the integration of the different systems and subsystems of mental health. Furthermore, the high level of sophistication in which specialized medicine continues to grow (imaging studies, genetic markers, transcranial stimulation, new psychotropics, integration between therapeutic models, etc.) forces us to be ahead of the curve.

At a state level, we have been working diligently for over a year on updating and modifying our Mental Health Law, and this year, the Mental Health Council was created by the state's government, educational institutions, civil associations, and professional bodies with the main purpose of providing care in a concerted way to the population under clearly studied parameters and creating lines against mental illnesses. At the same time, government and health institutions are working together to strengthen assistance programs for the population through training (performed by experts in mental health), as well as prevention and early detection programs.

Following the task of raising awareness on the importance of mental health, the Department of Psychiatry at the "Dr. Jose E. Gonzalez" University Hospital and the School of Medicine has made significant advances on the subject. We work alongside the ViceDean of Undergraduate Studies with the Mental Health Class as an optional subject, which brings school training in basic tools such as self-esteem, assertiveness, problem-solving, expressing emotions, and mindfulness. Subjects such as psychiatry, sex education, and discussion workshops close the distance between physicians in training, mental health professionals, and psychiatry specialists focused on the prevention of psychopathology. The School of Medicine hosts the PROZIQUE group, consisting of undergraduate students who promote mental health with 6-month courses of psychoeducation. We support the PASSWORD program at the School of Medicine, some of whose objectives are early detection, support, and treatment of student mental health.

With the different departments at the University Hospital, we continuously work to produce scientific research as a whole, as well as the training of its

\section{Correspondence:}

*Stefan Fernández-Zambrano

E-mail: stefanstefan@ hotmail.com
Available online: 09-12-2019

Date of acceptance: 08-10-2019 DOI: 10.24875/RMU.M19000036
Medicina Universitaria. 2019;21(4):134-135 www.medicinauniversitaria.org

列 (http://creativecommons.org/licenses/by-nc-nd/4.0/). 
residents in topics regarding the mental health of patients within their framework. The department of psychiatry coordinates and provides the space for Liaison psychiatry, this is used to care for hospitalized patients or follow-up patients in the general hospital area who require psychiatric management, and they also have a support group for residents of the different specialties who require help regarding their mental health.

Among the subjects that have been a constant in the training and awareness-raising in the different medical specialties are the empathy, the physicians ought to have toward their patients, as well as having the necessary skills to perform a correct referral to the Psychiatry Service when required, providing proper sensitization of the patient on the subject without having him/her become upset with their treating physician as a result of being considered "crazy," which could result in the abandonment of all sorts of treatment. If we add the factor of personality pathology to the resistance and difficulty involved in making an adequate referral of the patient to accomplish an improvement in their mental health, we find as a result patients who end up conflicting with and excising the entire work team with unnecessary studies and procedures, with a polypharmacy approach, multiple diagnoses, and prosecuting their physicians and hospitals, as mentioned in depth by Dr. Garza Guerrero in his article.

Originally, we started from an American model, where psychiatry is managed from a biological aspect with a strong emphasis on the patient's individual aspects. Today, at the Department of Psychiatry of the University Hospital, we operate in the biopsychosocial model, putting an emphasis on personality pathology, the reinsertion of the patient into the community, and family inclusion to the treatment.
Some of the aspects that invite us to continuously improve our attention models toward mental health are the results, we find in the follow-up of outpatients. Dr. Juarez Treviño shows in her research that only $30 \%$ of patients seen in crisis intervention continued their treatment for 6 months, showing limited adherence to treatment, with similar results to those described in literature. This study also makes a reference that just as with pharmacological treatments, non-adherence to treatment in psychotherapy is highly similar.

Another major factor to consider is the number of readmissions; one patient may present in the course of his/her psychiatric pathology. The more emphasis is placed on managing the patient in an integral way and facilitating access to health-care sites designed for the optimal benefit of the patients, the better the result concerning control that the patient may develop over his pathology.

Taking the aforementioned into consideration, and advised by the Centre Hospitalier de Sainte Anne, in Paris, as part of a collaboration agreement with said institution, today, at the department of psychiatry, we are aiming our efforts at accomplishing the following objectives: (1) the creation of crisis intervention centers inserted into the communities and outside the hospital environment, humanizing psychiatric care, and allowing for shorter internments in these centers and (2) to offer daily extra hospital stays, strategically located within the metropolitan area so that the patient can rely on a specialized network for his/her functional maintenance and social reinsertion. This model would complement the hospital approach since the objective is not to substitute it but to strengthen the resources available for the patient, with the purpose of preventing severe relapses in their pathology resulting in long periods of internment. 